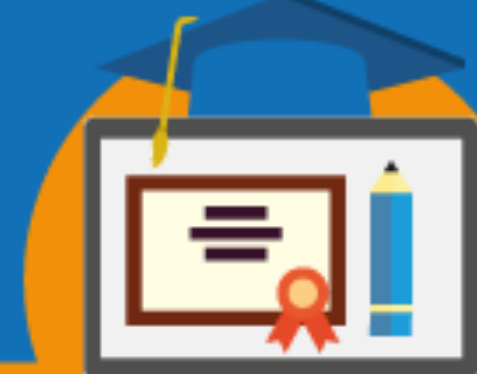

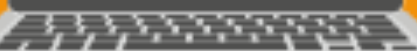

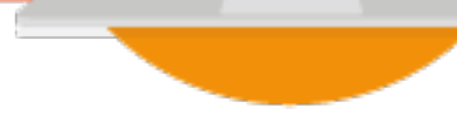

\section{CARACTERÍSTICAS PARA A AUTOAVALIAÇÃO INSTITUCIONAL DA EAD: UMA REFLEX̃̃O TEÓRICA}

\author{
Flávia Magalhães Freire \\ Centro Universitário UniAraguaia \\ flaviamf.ead@gmail.com \\ Leandro Vasconcelos Baptista \\ Centro Universitário UniAraguaia \\ leovbio@gmail.com
}

Eixo 2: Avaliação na EAD

Resumo: A autoavaliação institucional pode ser entendida como uma ferramenta para o autoconhecimento e autodesenvolvimento das IES de acordo com seus objetivos próprios, o que é fundamental quando se pensa as políticas neoliberais que regem a política educacional no Brasil contemporâneo. O presente trabalho visa elaborar características para que a autoavaliação da $\mathrm{EaD}$ se faça de acordo com características próprias da modalidade. A pesquisa desenvolvida foi bibliográfica e documental. A conclusão é que elementos como polos $\mathrm{EaD}$, infraestrutural virtual e física, equipe docente com destaque para o trabalho de tutoria e PPP devem ser avaliados nesse processo.

Palavras-chave: Educação a distância. Autoavaliação. Educação superior.

\section{Introdução}

Percebe-se hoje, segundo Lima et al. (2014), que as propostas dos governos com características neoliberais, ao longo da história, conduziram o Estado a uma mudança organizacional e política na sociedade que vem influenciando diretamente a educação brasileira. Nesse contexto, educação e mercado passam a ter uma relação íntima que direciona os processos formativos no país à uma lógica capitalista, principalmente por meio da Educação a Distância (EaD) que passa a ser vista, segundo Malanchen (2007, p.211), enquanto “instrumento para o desenvolvimento econômico, para o ajustamento dos indivíduos ao chamado mercado de trabalho, deixando-se em segundo plano a questão da educação como 


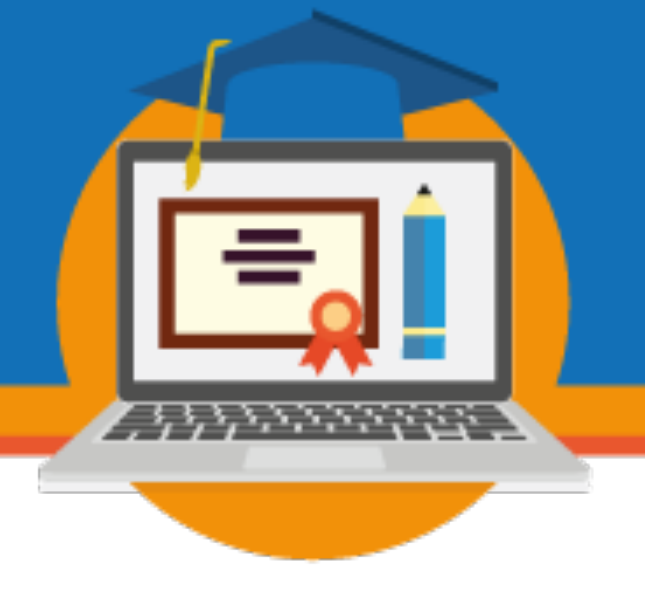

instrumento de emancipação humana".

Definida enquanto uma modalidade educacional em que a mediação didáticopedagógica ocorre com a utilização de meios e tecnologias de informação e comunicação, com características, avaliação e políticas específicas (BRASIL, 2017), a EaD apresenta em seu discurso político a evidência do processo de democratização e desenvolvimento da educação brasileira. No entanto, o que se percebe é um discurso esvaziado de seu conteúdo social, despolitizado e formal que sustenta a lógica hegemônica (MALANCHEN, 2007), bem como não considera as particularidades de implementação e desenvolvimento da mesma (FREIRE, 2018).

Corroborando com Holfing (2001), esse direcionamento político-discursivo acaba por atrelar ao Estado uma conduta de manutenção e reprodução de condições que são elementares para o livre acúmulo do capital, conduzindo a formação brasileira ao contexto da economia nacional e internacional com base na informatização e competitividade. Assim, os processos de implementação, bem como de autoavaliação de cursos oferecidos na modalidade EAD devem ter um olhar que busque conduzir essa modalidade para além das necessidades do capital, levando em consideração a essência de sua institucionalização.

Assim, questiona-se: compreendendo a EaD enquanto modalidade de ensino diferente da educação presencial, quais elementos devem ser considerados no processo de autoavaliação institucional, tendo em vista que os documentos oficiais apresentam a necessidade de políticas de implementação, avaliação e desenvolvimento compatíveis?

Nesse contexto, o presente trabalho se caracteriza enquanto uma análise teórica acerca dos elementos que podem ser considerados essenciais para a autoavaliação institucional da $\mathrm{EaD}$, partindo de uma pesquisa mais ampla realizada por Freire (2018). Para tanto, serão apresentadas discussões sobre as características da Avaliação Institucional no país, bem como seus reflexos no processo de autoavaliação da EaD. 


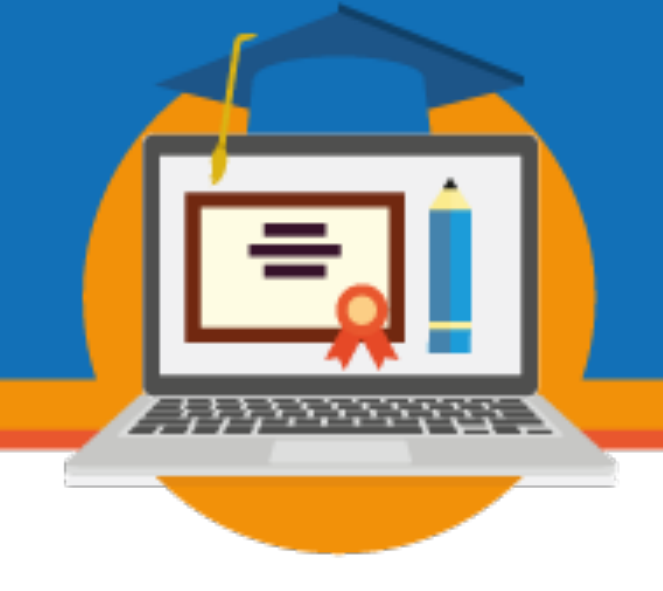

\section{A Avaliação Institucional no Brasil}

De acordo com Afonso (2013), considera-se que o Brasil está inserido no conceito de "Estado-avaliador", estabelecendo suas políticas educacionais de acordo com princípios que são impostos pelo mercado, o que faz com que esteja diretamente ligado à lógica capitalista. De acordo com essa definição, o "pós-Estado-avaliador", que se caracteriza enquanto a terceira fase - esquematizada por ele -, afirma a inserção do Estado-nação nos processos de transnacionalização da educação, com avaliação regulatória que se compara entre diferentes países.

Freire (2018) entende que, no Brasil, o “pós-Estado-avaliador” de Afonso (2013) mescla-se com uma Fase Transitória, caracterizada também por privatizações; avaliação formativa somada a iniciativas de controle por parte do Estado; estandardização curricular pautada pelos resultados da avaliação, entre outros.

A partir dos anos 80 , percebe-se que foi iniciado um processo que instituía a avaliação como uma política regulatória no âmbito da educação brasileira, tendo por base a abertura do país ao mercado internacional. Nesse sentido, foram apontadas as propostas de avaliação voltadas para a educação superior, representadas pelos documentos: 1. Programa de Avaliação da Reforma Universitária (Paru - 1983); 2. Relatório nomeado "Uma nova política para a Educação Superior brasileira", publicado pela Comissão Nacional de Reformulação da Educação Superior (Cnres) em 1985; 3. Relatório do Grupo Executivo para a Reformulação da Educação Superior (1986); 4. Programa de Avaliação Institucional das Universidades Brasileiras (Paiub - 1993); 5. O Exame Nacional de Cursos (ENC/Provão - 1996) e, por fim; 6. O próprio Sistema Nacional de Avaliação da Educação Superior (Sinaes), de 2004, em voga até os dias de hoje.

O Sinaes, em especial, passou a vigorar a partir da Lei ${ }^{\circ} 10.861$, de 14 de abril de 2004, e se constitui por três elementos básicos: I) Avaliação institucional: representada pela autoavaliação - avaliação interna, orientada pelas Comissões Próprias de Avaliação (CPA) de cada instituição e pela avaliação externa, atribuição dos avaliadores do Banco de Avaliadores

\section{SEMINÁRIO DE EDUCAÇÃO A DISTÂNCIA}

Diálogos sobre EaD e uso das TDIC na educação: regulamentação em tempos recentes 3 a 6 de novembro de 2020 - Brasília/DF - Online 


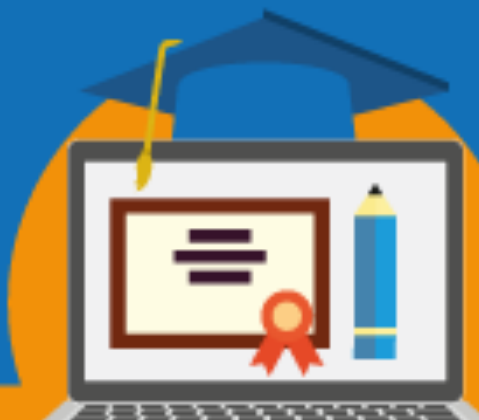

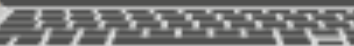

r

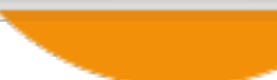

do Sinaes (Basis); II) Avaliações de curso: realizadas pelo Ministério da Educação juntamente com o Instituto Nacional de Estudos e Pesquisas Educacionais Anísio Teixeira (INEP), o Conselho Nacional de Educação (CNE) e pela Comissão Nacional de Avaliação da Educação Superior (Conaes) e; III) Avaliação do desempenho dos estudantes, executada por meio do Exame Nacional de Desempenho dos Estudantes e seus instrumentos específicos - questionário do estudante, questionário dos coordenadores de curso e questionário de percepção da prova (BRASIL, 2004).

Nesse contexto, espera-se que os processos de autoavaliação das Instituições de Ensino Superior (IES) no Brasil contemplem a EaD enquanto modalidade de ensino diferente da educação presencial, considerando suas especificidades de implementação, regulação e desenvolvimento.

\section{Características da Autoavaliação da EaD}

A EAD, que se apresenta enquanto uma modalidade educacional, segundo o Decreto $n^{\circ}$ 9.057, de 25 de maio de 2017, demanda que suas especificidades sejam consideradas nos processos de autoavaliação institucional. Assim, apresenta-se enquanto exigência a reflexão e discussão sobre os parâmetros e critérios que devem ser considerados ao se pensar a EaD no contexto da autoavaliação.

O Sinaes, estabelecido com a finalidade de estruturar e orientar o processo nacional de avaliação das instituições de ensino superior, dos cursos de graduação e do desempenho dos estudantes, entre outros objetivos, como desenvolver a qualidade do ensino superior, determina também os processos de autoavaliação institucional. De acordo com seu art. $3^{\circ}$ e $\S 2^{\circ}$, a autoavaliação, em conjunto com a avaliação externa in loco fazem parte da avaliação das IES do país. A autoavaliação deve ser conduzida pela CPA, gerida pela própria IES e que tenha autonomia em relação aos demais órgãos colegiados (BRASIL, 2004).

Considera-se, pois, que o processo de autoavaliação, determinado nos documentos regulatórios, é de responsabilidade de cada instituição. Estruturas, dimensões, atividades, 


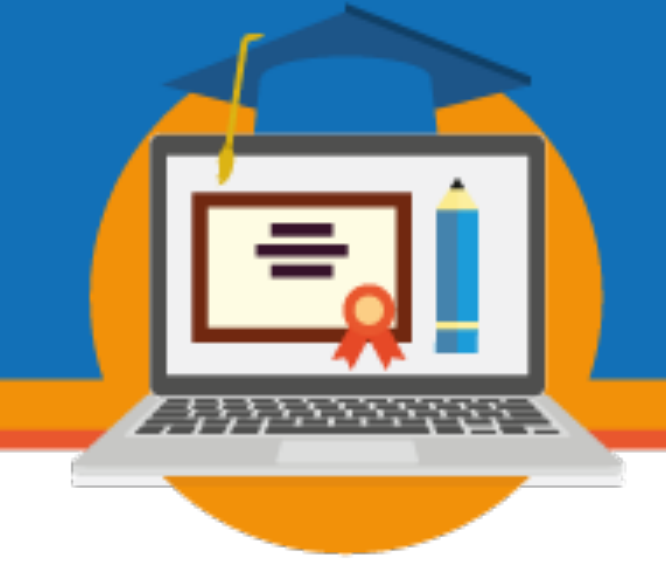

funções e finalidades da IES são o objeto de análise da avaliação institucional. Nesse aspecto, deve-se ter em conta os elementos da administração, os compromissos sociais, a relação ensinopesquisa-extensão, etc. Logo, estudantes, professores, funcionários e membros da comunidade externa (convidados ou designados) se caracterizam enquanto os sujeitos primordiais do processo de autoavaliação institucional (BRASIL, 2009).

Nesse contexto, os objetivos da autoavaliação, através do Sinaes, se caracterizam pela: produção de conhecimentos específicos da própria instituição para a realização das finalidades essenciais do processo educativo; identificação das causalidades dos problemas e deficiências da IES; aumento da consciência pedagógica e das relações educativas, bem como da capacidade profissional dos professores; efetivação da vinculação da instituição com seu entorno social e a comunidade externa; julgamento da relevância de suas atividades científicas e seus produtos à sociedade; prestação de contas à sociedade, justificando publicamente sua existência e; fornecimento das informações que sejam necessárias ao conhecimento do Estado e da população (BRASIL, 2009).

Assim a autoavaliação deve proporcionar conhecimentos basilares que permitam a expansão do engajamento profissional, possibilitando que sejam realizadas análises a respeito do trabalho desenvolvido na IES e proporcionando ações de melhoria do quadro de trabalhadores e da estrutura física e pedagógica da instituição. Por isso os processos de autoavaliação devem ser permanentes, gerando uma cultura sempre presente nas estruturas da organização educacional do país (BRASIL, 2009).

Entendendo o funcionamento da autoavaliação, retorna-se ao art. $3^{\circ}$ do Sinaes, que explicita 10 dimensões a serem consideradas no processo de avaliação, sendo elas:

I - a missão e o plano de desenvolvimento institucional;

II - a política para o ensino, a pesquisa, a pós-graduação, a extensão e as respectivas formas de operacionalização, incluídos os procedimentos para estímulo à produção acadêmica, as bolsas de pesquisa, de monitoria e demais modalidades;

III - a responsabilidade social da instituição, considerada especialmente no que se refere à sua contribuição em relação à inclusão social, ao desenvolvimento econômico e social, à defesa do meio ambiente, da memória cultural, da produção artística e do patrimônio cultural;

IV - a comunicação com a sociedade;

\section{SEMINÁRIO DE EDUCAÇÃO A DISTÂNCIA}




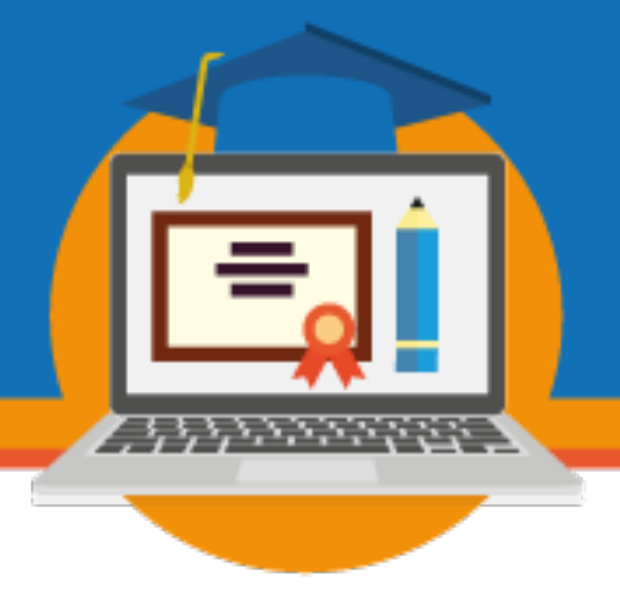

$\mathrm{V}$ - as políticas de pessoal, as carreiras do corpo docente e do corpo técnico-administrativo, seu aperfeiçoamento, desenvolvimento profissional e suas condições de trabalho;

VI - organização e gestão da instituição, especialmente o funcionamento e representatividade dos colegiados, sua independência e autonomia na relação com a mantenedora, e a participação dos segmentos da comunidade universitária nos processos decisórios;

VII - infra-estrutura física, especialmente a de ensino e de pesquisa, biblioteca, recursos de informação e comunicação;

VIII - planejamento e avaliação, especialmente os processos, resultados e eficácia da auto-avaliação institucional;

IX - políticas de atendimento aos estudantes;

$\mathrm{X}$ - sustentabilidade financeira, tendo em vista o significado social da continuidade dos compromissos na oferta da educação superior. (BRASIL, 2004).

Percebe-se, dessa maneira, que o Sinaes tenta abarcar de forma global os mais diferentes aspectos estruturais e humanos que envolvem o processo da educação superior no Brasil. Mari et al. (2017) sugerem que essas dimensões, quando pensada uma autoavaliação institucional da $\mathrm{EaD}$, sejam aglomeradas em cinco eixos, tendo em vista suas especificidades gerais:

a) Eixo 1: Planejamento e Avaliação Institucional (contempla a dimensão 8);

b) Eixo 2: Desenvolvimento Institucional (contempla as dimensões 1 e 3);

c) Eixo 3: Políticas Acadêmicas (contempla as dimensões 2, 4 e 9);

d) Eixo 4: Políticas de Gestão (contempla as dimensões 5, 6 e 10);

e) Eixo 5: Infraestrutura Física (contempla a dimensão 7);

Os eixos apresentados abordam tanto o planejamento educacional, como políticas da instituição em relação à modalidade, inclusão da sociedade, atuação de professores, discentes e pessoal administrativo e infraestrutura. Dentro desses eixos é possível refletir, então, sobre os elementos constituintes da $\mathrm{EaD}$ e seus direcionamentos dentro do processo de autoavaliação institucional.

Nesse contexto, Mari et al. (2017) sugerem que o instrumento para a autoavaliação institucional da EaD nas IES deve englobar questões como: instalações do polos de apoio presenciais; infraestrutura virtual; autoavaliação do respondente; equipe acadêmica; e avaliação da própria avaliação, ou seja, autoavaliação do questionário e da avaliação institucional. Os Referenciais de Qualidade para a Educação a Distância (2007), em concordância com os autores, apontam que o processo de autoavaliação deve incluir os aspectos de organização 
didático-pedagógica; corpo docente, corpo de tutores, corpo técnico-administrativo e discentes; e instalações físicas (BRASIL, 2007).

De acordo com Freire (2018), ainda que haja discussões acerca dos critérios para a autoavaliação institucional da $\mathrm{EaD}$, essa concepção ainda se caracteriza enquanto um quebracabeça formado por diferentes documentos oficiais: Leis de Diretrizes e Bases da Educação, Sinaes, Referenciais de Qualidade para a Educação Superior a Distância, artigos de diferentes autores, entre outros. No entanto, esse fato se faz coerente, tendo em vista o pequeno espaço de tempo de institucionalização da $\mathrm{EaD}$ no país, bem como as políticas descontínuas que configuram a educação brasileira.

Inicialmente, para que se tenha um direcionamento mais concreto acerca da autoavaliação institucional para a EaD, é possível apreender termos gerais que devem ser considerados: a diferenciação entre as modalidades presencial e a distância nos processos da instituição; a concepção dos cursos nessa modalidade em um Projeto Político Pedagógico (PPP) bem estruturado; a questão dos polos EaD; e a organização didático-pedagógica como um todo. Nesse sentido, percebe-se que a educação a distância demanda atenção específica no processo de autoavaliação institucional e em outros aspectos para sua caracterização enquanto modalidade de ensino diferente da educação presencial.

Adentrando em especificidades, Freire (2018) destaca também aspectos como a elaboração de um PPP que contemple a modalidade, incluindo concepção de educação, tecnologia e currículo no processo de ensino e aprendizagem; sistemas de comunicação a serem utilizados no curso a distância; material didático específico e não adaptado do utilizado na modalidade presencial; avaliação que considere o contexto pedagógico dos discentes; equipe multidisciplinar, essencial para a estruturação de um curso a distância de qualidade; infraestrutura de apoio; gestão acadêmico-administrativa e sustentabilidade financeira. Com o PPP que contemple esses tópicos é possível ter elementos para entender o que se pode esperar do curso, e, assim, ter condições de avaliá-lo de forma qualitativa.

Outra característica que favorece a autoavaliação da EaD é possuir representantes da modalidade na CPA, na intenção de reverter os dados levantados em questionários específicos 
voltados para a modalidade e torná-los objeto de análise e tomada de decisão também pode favorecer um maior entendimento sobre os funcionamentos e processos da modalidade (FREIRE, 2018). Além disso, destaca-se ainda o papel da tutoria no contexto da autoavaliação que, segundo Freire (2018), pode também ser considerado enquanto elemento essencial para o funcionamento dos cursos oferecidos na modalidade $\mathrm{EaD}$. No entanto, cabe considerar que ele não se configura enquanto a única figura responsável pelo processo de ensino-aprendizagem nesse contexto, mas parte de toda a complexidade que se envolve a modalidade de EaD no país (FREIRE, 2018).

Dessa forma, essas são algumas das características que devem ser consideradas ao desenvolver um processo de autoavaliação da EaD. Torna-se essencial, a partir do exposto, considerar sempre que a EaD apresenta especificidades que merecem atenção para a oferta de uma formação que não atenda apenas as necessidades do mercado, mas que também atenda ao discurso de uma formação democrática e de qualidade para a população brasileira.

\section{Considerações Finais}

A autoavaliação institucional é uma peça importante no contexto do Estado-avaliador descrito por Afonso (2013). Apesar de identificarmos iniciativas fundamentalmente voltadas para a política neoliberal, essa avaliação pode trazer uma oportunidade de autoconhecimento e autorregulação no âmbito das IES, permitindo que se desenvolva mais de acordo com seus próprios interesses e objetivos.

Dessa maneira, é importante que a EaD seja pensada de acordo com suas características específicas. É preciso que haja, assim, uma autoavaliação institucional que trabalhe segundo as necessidades da modalidade. O presente trabalho busca fazer um esboço das características e quais tópicos devem estar inclusos na realização dessa autoavaliação.

Identificam-se, então, aspectos como elaboração de um Projeto Político Pedagógico voltado para os cursos da educação a distância, questões avaliativas sobre os polos EaD, análise do trabalho dos tutores, da plataforma utilizada e do material didático disponibilizado. A própria 


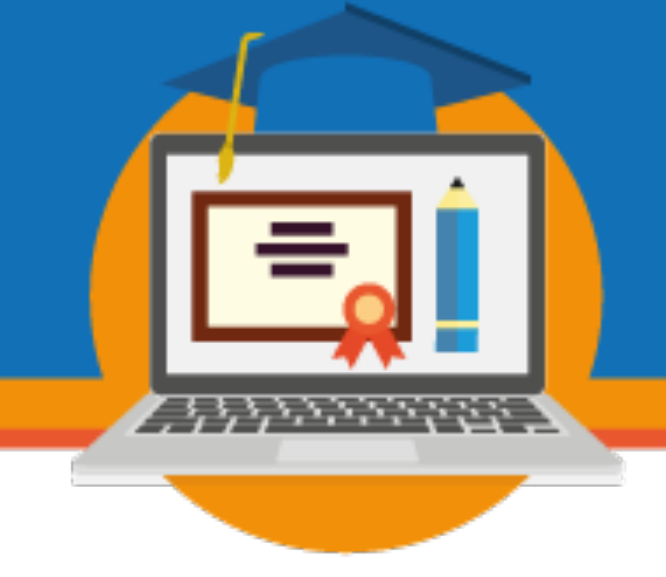

equipe acadêmica, instalações físicas e procedimentos da avaliação (metaavaliação) também são elementos que devem entrar na autoavaliação institucional.

Com base nas reflexões apresentadas até aqui, percebe-se que a $\mathrm{EaD}$, considerada enquanto uma modalidade de ensino, ainda está vinculada aos processos de autoavaliação institucional da educação presencial, desconsiderando alguns aspectos importantes que desenvolvimento dessa modalidade de ensino. Assim, é fundamental que a autoavaliação institucional inclua elementos aqui identificados que são particulares à modalidade, e outros a serem ainda pensados, permitindo que fraquezas e possibilidades sejam reconhecidos e, assim, seja possível que sejam pensados e desenvolvidos na instituição.

\section{Referências}

AFONSO, Almerindo Janela. Mudanças no Estado-avaliador: comparativismo internacional e teoria da modernização revisitada. Revista Brasileira de Educação, v. 18, n. 53 abr.-jun. 2013. Disponível em: <http://www.scielo.br/pdf/rbedu/v18n53/02.pdf>. Acesso em: 13 fev. 2020.

BRASIL. Decreto $\mathbf{n}^{0}$ 9.057, de 25 de maio de 2017. Regulamenta o art. 80 da Lei ${ }^{\circ}$ 9.394, de 20 de dezembro de 1996, que estabelece as diretrizes e bases da educação nacional. Disponível em http://www.planalto.gov.br/ccivil 03/ Ato2015-2018/2017/Decreto/D9057.htm. Acesso em 15 fev. 2020.

BRASIL. Lei no 10.861, de 14 de abril de 2004. Institui o Sistema Nacional de Avaliação da Educação Superior - SINAES e dá outras providências. Diário Oficial da União, Brasília, DF: Imprensa Nacional, ano 141, n. 72, p. 3.15 abr. 2004. Seção 1. Disponível em: http://www.planalto.gov.br/ccivil 03/ ato2004-2006/2004/lei/110.861.htm. Acesso em $10 \mathrm{fev}$. 2020.

BRASIL. Ministério da Educação (MEC). SINAES - Sistema Nacional de Avaliação da Educação Superior: da concepção à regulamentação. 5. ed., revisada e ampliada. Brasília: Instituto Nacional de Estudos e Pesquisas Educacionais Anísio Teixeira, 2009. Disponível http://portal.inep.gov.br/documents/186968/484109/SINAES+-

+Sistema+Nacional+de+Avalia\%C3\%A7\%C3\%A3o+da+Educa\%C3\%A7\%C3\%A3o+Superi or+Da+Concep $\% \mathrm{C} 3 \% \mathrm{~A} 7 \% \mathrm{C} 3 \% \mathrm{~A} 3 \mathrm{o}+\% \mathrm{C} 3 \% \mathrm{~A} 0+\mathrm{Regulamenta} \% \mathrm{C} 3 \% \mathrm{~A} 7 \% \mathrm{C} 3 \% \mathrm{~A} 3 \mathrm{o}+5 \mathrm{a}+\mathrm{ed}+$ amp/d98724bf-b529-4a88-a5f9-e62b9d6f9ebc?version=1.4. Acesso em 10 fev. .2020. 


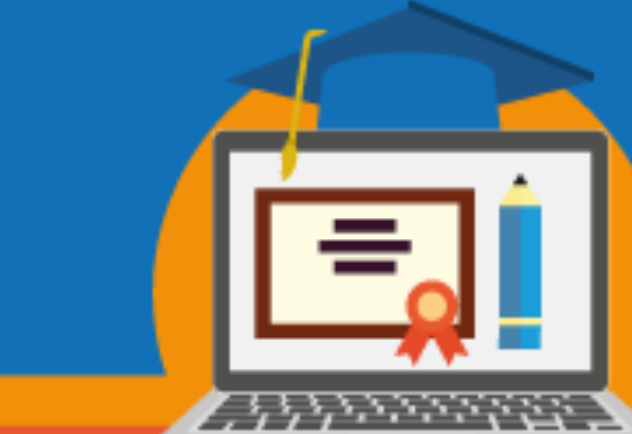

BRASIL. Ministério da Educação (MEC). Referenciais de Qualidade para Educação Superior a Distância. Portal MEC, 2007. Disponível em: http://portal.mec.gov.br/seed/arquivos/pdf/legislacao/refEAD1.pdf. Acesso em: 11 fev. 2019.

FREIRE, Flávia Magalhães. Trajetória e mecanismos da autoavaliação institucional de cursos da modalidade a distância na Universidade Federal de Goiás. 206 p. Dissertação (Mestrado em Educação) - Universidade Federal de Goiás, 2018.

HOLFING, Eloísa de Matos. Estado e políticas (públicas) sociais. Cadernos de Educação CEDES. Campinas, v. 21, n. 55, nov. 2001.

LIMA JÚNIOR, Paulo; DECONTO, Diomar Caríssimo Selli; ANDRELLA NETO, Ricieri; CAVALCANTI, Cláudio José de Holanda; OSTERMANN, Fernanda. Marx como referencial para análise de relações entre Ciência, Tecnologia e Sociedade. Ciência Educação, Bauru, v. 20, n. 1, p. 175-194, mar. 2014.

MARI, M. M.; RIBEIRO, V. C.; PARANÀ, J. S.; SANTOS, E. J.; MELO, M. J. S. Proposta de um instrumento para a autoavaliação institucional em EAD. JNT - Facit Business and Techonology Journal, v. 1, n.1, p. 1-22, 2017. Disponível em: http://revistas.faculdadefacit.edu.br/index.php/JNT/article/view/152/156. Acesso em: 06 fev. 2020. 